\title{
nature
}

\section{The centre needs to hold}

Research ministers met for a seminar in London this week to discuss how to improve the handling of Europeanlevel research. The solution lies in steady and targeted reforms to practices in Brussels.

T he relative lack of opposition with which many Europeans appear to have accepted the imminent introduction of a single currency — the unimaginatively named Euro — has surprised even some of its strongest critics. The general mood seems to reflect a passive acceptance that, like democracy itself, it may not be a perfect way of running things, but it is the best option we know of.

A similar judgement might be made about the management of the joint research programmes of the European Union. There are many valid criticisms of the way Brussels handles research funds. Excessive form filling, the need to meet obscure bureaucratic requirements, lengthy delays in reaching decisions, high rejection rates, excessive political interference, and remoteness from national research priorities and the activities of national research agencies; almost every European researcher who has applied for such funds, whether successful or not, has his or her own horror story to tell.

Unsurprisingly, such complaints have encouraged a search for alternative, sometimes radical, solutions. Some have been arguing, with considerable logic on their side, that more responsibility for the management of research programmes should be contracted out by the European Commission to the research community through bodies such as the European Science Foundation. Others believe that national organizations should be allowed to play a greater role in helping to manage European-level funds. Perhaps most provocatively, the French research minister, Claude Allègre, has recently been suggesting a full-scale devolution of some management responsibilities from Brussels to national agencies, such as France's own Centre Nationale de la Recherche Scientifique.

Some movement in these directions would undoubtedly be beneficial. Centralized bureaucracies can easily become isolated from those they are intended to serve. And experiments such as the AMICA consortium, which has been given responsibility for allocating research funds in the field of plant biology, have been of substantial value. But an excessive devolution of responsibility away from Brussels would be a mistake at a time when Europe needs more, not less, strategic thinking about the development of its research base.

Take, for example, the European Union's programme on Training and Mobility of Researchers. Suggestions have been heard recently that responsibility for fellowships awarded through this programme should be passed back to national organizations able to handle them in a more 'rational' manner. That might work in countries with wellorganized national institutions for handling such schemes. For others who prefer to work in a less centralized way — and who find the current arrangement largely satisfactory, particularly in the way it allows a genuinely European level of evaluation and assessment such dramatic change holds little attraction.

Not even the most hardened commissioner would argue that Brussels is perfect. The agenda of a top-level seminar attended by almost a dozen research ministers in London this week (see page 849) was replete with topics on which the commission could do better. These range from the trivial but irritating - such as why, in an age of electronic communication, so many application forms still require to be painstakingly typed - to strategic issues about ensuring that the research projects in the forthcoming Fifth Framework Programme genuinely reflect the interests of potential users of such research.

There are many ways in which the commission needs shaking up in its handling of research; by concentrating the minds of his colleagues on the Council of Ministers on some of these, Allègre has already performed a useful service. But many in the commission are well aware of such needs, and are striving to address them. Critics also sometimes ignore the complex political pressures under which the commission is required to operate. Even researchers, for example, appreciate that applying the concept of 'cohesion' may not produce the most cost-effective science. But it has other advantages in terms of disseminating scientific and technical expertise. There are times when deliberate, well-planned reform can achieve much more than revolutionary rhetoric. This is what Brussels now needs; not ambitious, and sometimes misguided, claims that others could do its job better.

\section{From art to image}

\section{As a series of articles changes direction, science's relevance to art is reaffirmed.}

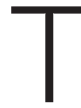
his issue sees the concluding article in the first part of a series by the art historian Martin Kemp. In previous articles, he has dealt with scientific ideas and perspectives embedded in 27 artists' handling of their subject matter. Such an approach is illuminating provided one understands the science (as Kemp clearly does), the art is worth looking at and analysing (as at least most of it has been), and especially where a writer delivers a highly focused presentation (as is inevitably required in a one-page format). On pages $875-876$, and at slightly greater length, Kemp places much of what he has discussed into a broader summarizing framework. Many readers will no doubt have already formed their own judgements. But the result of the series has surely been at least a broadened range of readers' awareness of artists and a deepened appreciation of how art works, as well as lively discussions in other fora, such as museums and galleries.
The series now shifts to the same art historian's perspective on the way scientific concepts and objects are visualized, starting next week with a discussion of the use of images in this journal. Kemp will subsequently deal with scientific images with the same three-week cyclical approach as previously: pre-twentieth century, classic twentieth century, contemporary.

Physicists in America, nervous about pseudoscience, are worrying about a proposed public statement (see page 849) which in draft form emphasizes science's objective and repeatable qualities, while (more controversially) welcoming complementary approaches to the understanding of nature. Kemp's series has illuminated artistic subjectivity and objectivity. In doing so, however, he has shown not that art assists scientific understanding, but that scientific insight can provide a fruitful stimulus to some of the most powerful of artistic interpretations. $\square$ 